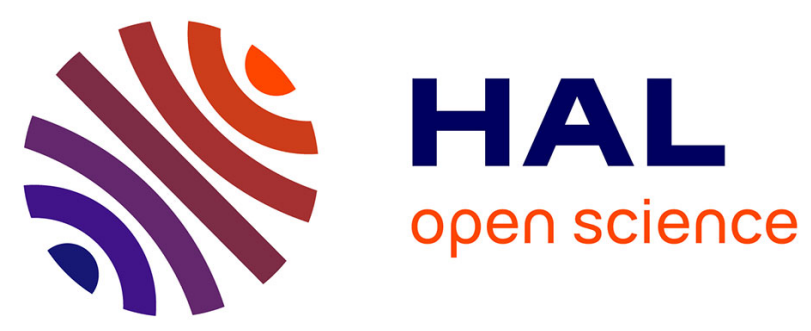

\title{
Dapagliflozin and Liraglutide therapies rapidly enhanced bone material properties and matrix biomechanics at bone formation site in a type 2 diabetic mouse model
}

\author{
Aleksandra Mieczkowska, Paul Millar, Daniel Chappard, Victor A Gault, \\ Guillaume Mabilleau
}

\section{To cite this version:}

Aleksandra Mieczkowska, Paul Millar, Daniel Chappard, Victor A Gault, Guillaume Mabilleau. Dapagliflozin and Liraglutide therapies rapidly enhanced bone material properties and matrix biomechanics at bone formation site in a type 2 diabetic mouse model. Calcified Tissue International, In press, $10.1007 / \mathrm{s} 00223-020-00720-4$. hal-02885562

\section{HAL Id: hal-02885562 \\ https://univ-angers.hal.science/hal-02885562}

Submitted on 30 Jun 2020

HAL is a multi-disciplinary open access archive for the deposit and dissemination of scientific research documents, whether they are published or not. The documents may come from teaching and research institutions in France or abroad, or from public or private research centers.
L'archive ouverte pluridisciplinaire HAL, est destinée au dépôt et à la diffusion de documents scientifiques de niveau recherche, publiés ou non, émanant des établissements d'enseignement et de recherche français ou étrangers, des laboratoires publics ou privés. 
Dapagliflozin and Liraglutide therapies rapidly enhanced bone material properties and matrix biomechanics at bone formation site in a type 2 diabetic mouse model

Aleksandra Mieczkowska ${ }^{1}$, Paul Millar ${ }^{2}$, Daniel Chappard ${ }^{1,3,4}$, Victor A. Gault², Guillaume Mabilleau 1,3,4

1 Groupe Etude Remodelage Osseux et biomatériaux, GEROM, UPRES EA 4658, UNIV Angers, SFR ICAT 4208, Institut de Biologie en Santé, Angers, France

2 School of Biomedical Sciences, University of Ulster, Coleraine, Northern Ireland, United Kingdom

3 Service Commun d'Imagerie et Analyses Microscopiques, SCIAM, UNIV Angers, SFR ICAT 4208, Institut de Biologie en Santé, Angers, France

4 Bone pathology unit, CHU Angers, 49933 Angers Cedex, France

Please send all correspondence to:

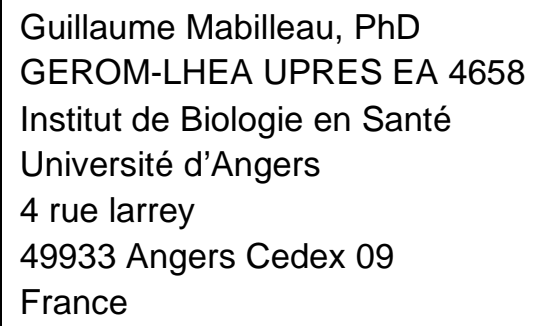

Abstract word count: 247 words

Manuscript word count: 4893 words

Number of references: 69

Number of figures: 5

Number of tables: 2

Short running title: anti-diabetic medications and bone quality

Keywords: Dapagliflozin, Liraglutide, Bone fragility, Bone material properties, Type 2 diabetes 


\section{ABSTRACT}

Aim: To compare head-to-head the effects of dapagliflozin and liraglutide on bone strength and bone material properties in a pre-clinical model of diabetes-obesity.

Materials and methods: Combined low-dose streptozotocin and high fat feeding were employed in mice to promote obesity, insulin resistance and hyperglycaemia. Mice were administered daily for 28 days with saline vehicle, $1 \mathrm{mg} / \mathrm{kg}$ dapagliflozin or $25 \mathrm{nmol} / \mathrm{kg}$ liraglutide. Bone strength was assessed by three-point bending and nanoindentation. Bone material properties were investigated by Fourier transform infrared microspectroscopy/imaging.

Results: Although diabetic controls presented with dramatic reductions in mechanical strength, no deterioration of bone microarchitecture was apparent. At the tissue level, significant alterations in phosphate/amide ratio, carbonate/phosphate ratio, tissue water content, crystal size index, collagen maturity and collagen glycation were observed and linked to alteration of matrix biomechanics. Dapagliflozin and liraglutide failed to improve bone strength by 3-point bending or bone microarchitecture during the 28-day-treatment period. At bone formation site, dapagliflozin enhanced phosphate/amide ratio, mineral maturity, and reduced tissue water content, crystal size index and collagen glycation. Liraglutide had significant effects on phosphate/amide ratio, tissue water content, crystal size index, mature collagen crosslinks, collagen maturity and collagen glycation. At bone formation site, both drugs modulated matrix biomechanics.

Conclusions: This study highlighted that these two molecules are effective in improving bone material properties and modulating matrix biomechanics at bone formation site. This study also highlighted that the resulting effects on bone material properties are not identical between dapagliflozin and liraglutide and not only mediated by lower blood glucose. 


\section{INTRODUCTION}

Type 2 diabetes mellitus (T2DM) affects approximately 425 million adults worldwide and projected figures for 2045 estimate a rise of up to $48 \%$ reaching 629 million adults [1]. T2DM is characterized by insulin and glucose intolerances that result in the development of chronic hyperglycaemia and hyperinsulinemia and is considered a risk factor for secondary osteoporosis [2]. In T2DM, the propensity for fracture is greater than would be predicted by bone mineral density alone suggesting possible alterations of bone microarchitecture or material properties [3]. Glucose-lowering agents that result in greater hypoglycaemic events and hence augment the risk of falls, may enhance fracture risk. Independent of hypoglycaemic events, antidiabetic agents may also influence skeletal physiology, as observed with thiazolidinediones that augment adipogenesis at the expense of osteoblastogenesis and osteocyte apoptosis [4].

Glucagon-like peptide-1 receptor agonists (GLP-1RAs) and sodium/glucose cotransporter 2 (SGLT2) inhibitors are among the most recent class of drugs approved for the treatment of T2DM. Both classes of antidiabetic agents contribute to reductions in fasting and postprandial glycaemia, $\mathrm{HbA}_{1 \mathrm{c}}$, systolic blood pressure and weight loss [5]. Interestingly, in opposition to what is observed with other newer glucose-lowering agents such as dipeptidylpeptidase-4 inhibitors, recent studies have indicated that several GLP-1RAs, including liraglutide and SGLT2i are capable of reducing major cardiovascular events, making these agents even more therapeutically attractive [6].

Intriguingly, a higher number of treatment-emergent bone fractures with canagliflozin and dapagliflozin have been reported in patients with T2DM $[7,8]$. However, the reason for higher fracture risk with SGLT2i is unclear and the effects of these compounds on bone strength, bone material properties and matrix biomechanics have not been thoroughly investigated. We hypothesize that SGLT2i lower bone strength by altering bone microarchitecture and/or tissue material properties. The primary goal of the present study was to compare head-to-head the effects of the SGLT2i, dapagliflozin, and GLP-1RA, liraglutide, on bone strength, material properties and matrix biomechanics in an animal model of T2DM induced by joint administration of a high fat diet and streptozotocin (STZ).

\section{MATERIAL AND METHODS}

\subsection{Animals}


All procedures were conducted according to UK Home Office Regulations (UK Animals Scientific Procedures Act 1986) and approved by Ulster University Animal Welfare and Ethical Review Body. Male Swiss mice (Hsd: NIHS background, Envigo, Oxon, UK) at 8-10 weeks of age were housed individually in an air-conditioned room at $22 \pm 2^{\circ} \mathrm{C}$ with a 12 -hour light/dark cycle and provided with tap water ad libitum. A group of 8 mice had free access to standard rodent chow (6.2\% fat, 18.6\% protein, total energy $13.0 \mathrm{~kJ} / \mathrm{g}$ ) and administered once daily with saline for the last 28 days (Lean+saline). Additionally, twenty-four mice had free access to a high fat diet (45\% fat, $20 \%$ protein; total energy $26.15 \mathrm{~kJ} / \mathrm{g}$; product code 824053; Special Diet Service, Witham, UK) ad libitum. Fourteen and seven days before commencing pharmacological interventions, these mice received $50 \mathrm{mg} / \mathrm{kg}$ i.p. streptozotocin (STZ) prepared in sodium citrate buffer $(\mathrm{pH}$ 4.5). Supplementary Figure 1 illustrates the design of the animal experiment. All animals exhibited fasting blood glucose concentration $>13 \mathrm{mmol} / \mathrm{L}$ and were recruited into the study and considered diabetic. Diabetic mice were randomly allocated into three groups ( $n=8 /$ group): Group 1 - Diabetic mice with saline vehicle (Diabetic+saline; $0.9 \% \mathrm{NaCl}$, i.p., once-daily); Group 2 - Diabetic mice with dapagliflozin (Diabetic+Dapaglifozin; $1 \mathrm{mg} / \mathrm{kg}$, per os, once-daily); Group 3 - Diabetic mice with liraglutide (Diabetic+Liraglutide; $25 \mathrm{nmol} / \mathrm{kg}$, i.p., once-daily). Dosing of $1 \mathrm{mg} / \mathrm{kg}$ dapagliflozin (p.o) and $25 \mathrm{nmol} / \mathrm{kg}$ liraglutide (i.p.) was based on previous literature $[9,10]$. Saline, dapagliflozin and liraglutide were administered for 28 days, a period that was previously shown to induced significant improvement in tissue material properties [11]. Ten and three days before sacrifice, animals were administered with calcein (10 mg/kg; i.p.). Among all SGLT2 inhibitors, dapagliflozin was chosen as at the time of the study, it presented the highest SGLT2 inhibition selectivity. Through the course of this study, blood glucose level was assessed every week in non-fasted mice. At the end of the study, an oral load of glucose (18 mmol/ $\mathrm{kg}$ ) was administered to mice after an initial fast of $\sim 12-\mathrm{h}$. Blood samples were collected from the tail vein as indicated below at 0-, 15-, 30-, 60- and 120-min post glucose administration. Insulin sensitivity test were also performed two days later by injecting intraperitoneally $25 \mathrm{U} / \mathrm{kg}$ bovine insulin to non-fasted mice. Blood glucose was measured as indicated below at 0-, 30and 60-min post-insulin administration. At necropsy, femurs were cleaned of soft tissues and stored either in saline-soaked gauze at $-20^{\circ} \mathrm{C}$ (bone strength assessment) or in $70 \%$ ethanol at $4^{\circ} \mathrm{C}$ (Fourier transform infrared microspectroscopy/imaging) until used.

\subsection{Biochemical analyses}


Blood samples were collected from the tail vein of conscious mice into chilled fluoride/heparin microcentrifuge tubes (Sarstedt, Numbrecht, Germany) and centrifuged at 13,000g for 30 seconds (Beckman Instruments, Galway Ireland). Glucose concentrations were measured using Ascencia Contour Blood Glucose Meter (Bayer healthcare) and plasma insulin determined using modified dextran-coated charcoal RIA [12].

\subsection{Three-point bending}

Three-point bending experiments were performed on left femurs after rehydrating bones at $4^{\circ} \mathrm{C}$ for $24 \mathrm{~h}$ and letting them warm up to room temperature $\left(22 \pm 2^{\circ} \mathrm{C}\right)$ for at least $6 \mathrm{~h}$. Femurs were loaded to failure at room temperature at $0.5 \mathrm{~mm} / \mathrm{min}$ using an Instron 5942 (Instron, Elancourt, France). The lower span length was set to $8 \mathrm{~mm}$. Femur length was measured with digital caliper using anatomical reference point (great trochanter, femoral condyle). The mean femur length was measured at $14 \mathrm{~mm}$ and did not vary between groups. The anterior surface was subjected to tension and the posterior surface to compression. Load and displacement were digitally recorded at a sampling rate of $100 \mathrm{~Hz}$ and measured using a $500 \mathrm{~N}$ load cell (Instron) with an accuracy down to $0.5 \mathrm{~N}$ (data supplied by Instron). The loaddisplacement curve was recorded and plotted with the Bluehill 3 software (Instron). Whole-bone biomechanical parameters were deduced from load-displacement curve. After three-point bending, left femur was fixed in 10\% formalin, analysed by microCT (see below) and tissue-level biomechanical parameters were calculated with beam theory equations.

\subsection{MicroCT and bone histomorphometry}

MicroCT analyses were performed after 3-point bending on left femurs with a Skyscan 1172 microtomograph (Bruker MicroCT, Kontich, Belgium) operated at $70 \mathrm{kV}, 100 \mu \mathrm{A}, 340-\mathrm{ms}$ integration time. The isotropic pixel size was fixed at $4 \mu \mathrm{m}$, the rotation step at $0.25^{\circ}$ and exposure was done with a $0.5-\mathrm{mm}$ aluminium filter. Each 3D reconstruction image dataset was binarized using global thresholding. Trabecular volume of interest ( $\mathrm{VOI}$ ) was located $0.5 \mathrm{~mm}$ above the distal growth plate and extended on 2-mm up to the diaphysis. Cortical volume of interest was positioned at the femur midshaft $4 \mathrm{~mm}$ above the distal growth plate and extended on $0.5 \mathrm{~mm}$ in upward and downward directions. All microCT parameters were determined according to guidelines and nomenclature proposed by the American Society for Bone and Mineral Research [13]. After microCT scans, femurs were embedded undecalcified in polymethylmethacrylate at $4^{\circ} \mathrm{C}$. Coronal sections of the distal half $(7-\mu \mathrm{m}$ thickness) 
were cut, stained with conventional bone staining (Goldner trichrome, toluidine blue, tartrate resistant acid phosphatase) and analysed by a trained bone pathologist blinded to the treatment group. Histomorphometrical parameters were assessed according to the guidelines provided by the American Society for Bone and Mineral Research [14].

\subsection{Fourier-transform infrared microspectroscopy and imaging}

Right femurs were embedded undecalcified in pMMA at $4^{\circ} \mathrm{C}$. Cross-sectional sections ( $1 \mu \mathrm{m}$-thick) of femur diaphysis, located $6 \mathrm{~mm}$ above the end of the distal condyle, were cut with a Histo diamond knife (Diatome Ltd, Nidau, Switzerland) mounted on a Leica UC7 ultramicrotome (Leica Microsystems SAS, Nanterre, France). Sections were deposited onto barium fluoride optical windows.

Fourier transform infrared microspectroscopy (FTIRM) was performed at bone formation site in cortical bone by recording infrared spectra only between double calcein labelling at periosteal and endosteal envelopes. Briefly, three spectra were recorded in both envelope per animal with a spectral resolution of $4 \mathrm{~cm}^{-1}$ on the range $750-2000 \mathrm{~cm}^{-1}$. A Bruker Vertex 70 spectrometer (Bruker optics, Ettlingen, Germany) was interfaced with a Bruker Hyperion 3000 infrared microscope equipped with a single element mercury-cadmium-telluride (MCT) detector cooled with liquid nitrogen. Each spectrum was corrected for Mie scattering with the RMieS-EMSC_v5 algorithm (kind gift of Prof Peter Gardner, University of Manchester, UK). Prior to being subjected to pMMA subtraction, the area of the 1715 $1745 \mathrm{~cm}^{-1}$ peak, corresponding to the $\mathrm{C}=\mathrm{O}$ vibration of pMMA, and the amide I band, located between $1590-1710 \mathrm{~cm}^{-1}$ were computed. After pMMA subtraction, spectra were vector normalized for the v1,v3 phosphate band, located between 900-1200 $\mathrm{cm}^{-1}$, and second derivative spectroscopy was applied to find the position of underlying peaks. Curve fitting was performed with a routine script in Matlab (The MathWorks, Natick, USA) using second derivative minima as a loading vector for subpeak locations. Supplementary table 1 summarizes peak assignment. The evaluated infrared spectral parameters were:

- Tissue water content, calculated as the area ratio of the pMMA peak $\left(1715-1745 \mathrm{~cm}^{-1}\right)$ to amide I (1590-1710 $\left.\mathrm{cm}^{-1}\right)$, both computed before pMMA subtraction, similar to nanoporosity computation from Raman spectra [15]. This approach takes advantage of the fact that water is replaced by pMMA during the embedding process, the computed ratio is used as a proxy for water content. In bone tissue, water generally exists within pores and bound to the matrix. Matrix-bound water is not a monolayer but rather a series of coordinated water molecules, the 
outermost of which may be removed by the tissue processing (dehydration through acetone, clearing with xylene and subsequent pMMA embedding). Thus, the tissue water content inferred in the present study may be loosely coordinated water, as well as water that was present in canaliculi in the studied voxel.;

- Phosphate/amide ratio, calculated as the ratio of areas of the v1, v3 phosphate band at 900$1200 \mathrm{~cm}^{-1}$ to the amide I band at $1585-1725 \mathrm{~cm}^{-1}$, both determined after pMMA subtraction;

- Carbonate/phosphate ratio, calculated as the ratio of the v2 carbonate band at $850-900 \mathrm{~cm}^{-1}$ to the v1,v3 phosphate band;

- mineral maturity calculated as the area ratio of the sub bands at $\sim 1030 \mathrm{~cm}^{-1}$ and $\sim 1110 \mathrm{~cm}^{-1}$ of the phosphate band;

- crystal size index, that increases with increased crystallite size, was determined as the area ratio of sub bands located at $\sim 1076 \mathrm{~cm}^{-1}$ and $\sim 1058 \mathrm{~cm}^{-1}[16]$;

- Collagen maturity determined as the area ratio of subbands peaking at $\sim 1660 \mathrm{~cm}^{-1}$ (mature crosslinks) and $\sim 1690 \mathrm{~cm}^{-1}$ (Immature crosslinks). The respective contribution of mature and immature crosslinks to total collagen crosslinks was computed to evaluate post-processing of collagen molecules as previously reported [17];

- collagen glycation index was determined after demineralization of bone sections as the area ratio of the $1032 \mathrm{~cm}^{-1}$ subband to amide I as previously validated [18]

No differences were evidenced between periosteal and endosteal envelopes and as such data presented hereafter corresponds to pooled data.

Fourier transform infrared imaging (FTIRI) was performed in the posterior quadrant of femur midshaft. A focal plan array detector (64x64 pixels) was preferred to the single element MCT detector in the experimental setup described above. A spectral hypercube on the range $900-2000 \mathrm{~cm}^{-1}$ was recorded for each pixel with a spectral resolution of $8 \mathrm{~cm}^{-1}$. The corresponding infrared image represented an area of 540 um $\times 540$ um with a $\sim 5-11$ um spatial resolution. Each spectrum was corrected for Mie scattering with the RMieS-EMSC_v5 algorithm. Prior to pMMA subtraction, the area of the 1715 - 1745 $\mathrm{cm}^{-1}$ peak, corresponding to the $\mathrm{C}=\mathrm{O}$ vibration of $\mathrm{pMMA}$, and the amide I band, located between 1590 - $1710 \mathrm{~cm}^{-1}$ were computed. After pMMA subtraction, spectra were vector normalized for the $\mathrm{v} 1, \mathrm{v} 3$ phosphate band, located between $900-1200 \mathrm{~cm}^{-1}$. The evaluated parameters were: 
- Tissue water content, calculated as the intensity ratio of the pMMA peak $\left(\sim 1730 \mathrm{~cm}^{-1}\right)$ to amide I $\left(\sim 1656 \mathrm{~cm}^{-1}\right)$, both computed before pMMA subtraction

- Phosphate/amide ratio, calculated as the ratio of areas of the v1, v3 phosphate band to the amide I band;

- Carbonate/phosphate ratio (intensity v3 carbonate located at $\sim 1415 \mathrm{~cm}^{-1} / 1030 \mathrm{~cm}^{-1}$ ) was computed after subtracting the organic matrix spectrum [19].

- Mineral maturity calculated as the intensity ratio at $1030 \mathrm{~cm}^{-1}$ and $1110 \mathrm{~cm}^{-1}$;

- Crystal size index as the intensity ratio at $1076 \mathrm{~cm}^{-1}$ and $1058 \mathrm{~cm}^{-1}$;

- Collagen maturity determined as the intensity ratio at $\sim 1660 \mathrm{~cm}^{-1}$ (mature crosslinks) and $\sim 1690$ $\mathrm{cm}^{-1}$ (Immature crosslinks).

- Collagen glycation index determined as the area ratio of the $\sim 1032 \mathrm{~cm}^{-1}$ subband to amide I.

Histogram distribution for each compositional parameter was plotted and the mean and full width at half maximum of the pixel distribution (excluding non-bone pixels) were computed and represented as mean and width.

\subsection{Nanoindentation}

Measurement of matrix biomechanics was performed by nanoindentation. This technique acquires force-displacement data of a pyramidal diamond indenter that is pressed onto a material sample. In opposition to three-point bending, nanoindentation is independent of bone geometry and microarchitecture. After cutting sections for FTIRI/FTIRM, pMMA blocks were polished to a 1- $\mu \mathrm{m}$ finish with diamond particles (Struers, France). After polishing, the sample surface was estimated at $10 \mathrm{um}$ from sections observed by FTIRI/FTIRM. The polished surface was examined with a confocal Leica SP8 microscope (Leica Microsystems, Nanterre, France) set at $488 \mathrm{~nm}$ for excitation and $515-580 \mathrm{~nm}$ for emission for the presence of double calcein labelling. Blocks were then subjected to rehydration in saline $24 \mathrm{~h}$ prior to nanoindentation testing at room temperature. Nanoindentation was performed with the $\mathrm{NHT}^{2}$-TTX system (Anton Paar, Les Ulis, France). Briefly, this system is composed of an epi-illumination microscope that allows precise examination of sample surface and marking of indentation location, a motorized stage, that allows translation of the sample from the epi-illumination microscope to the nanoindentation probe. Indentation were made between double calcein labelling with a depth of 900 nm. At maximum load, a holding period of 15 seconds was applied to avoid creeping of the bone 
material. The following material properties at the matrix-level, maximum load, indentation modulus, hardness and work of indentation, were determined according to Oliver and Pharr [20].

\subsection{Statistical analysis}

All data were analysed using Prism 6.0 (GraphPad Software Inc., La Jolla, CA). Equal variance between groups were tested with the Brown-Forsythe test. One-way ANOVA and Tukey's multiple comparison tests, with a single pooled variance, were employed to test for significance in any of the studied parameters. Differences at $p$ equal to or less than 0.05 were considered significant.

\section{RESULTS}

\subsection{Short-term treatment of dapagliflozin or liraglutide reduced fasted blood glucose level and} insulin resistance

As expected, saline-treated diabetic mice presented with high blood glucose levels through the full course of this study (Figure 1A). Administration of dapagliflozin or liraglutide, significantly reduced blood glucose levels from the $8^{\text {th }}$ day of treatment onwards (Figure 1A). Oral glucose tolerance test revealed that saline-treated diabetic animals exhibited higher AUC glucose and AUC plasma insulin (Figure 1BC). Twenty-eight-day treatment with dapagliflozin or liraglutide significantly reduced glucose excursion during the oral glucose tolerance test and a lower insulin response suggesting improvements in glucose metabolism. Similarly, treatment with dapagliflozin or liraglutide led to significant improvements in insulin sensitivity compared to saline-treated diabetic animals (Figure 1D).

\subsection{Short-term treatment with dapagliflozin or liraglutide did not restore significantly bone strength in diabetic animals}

We examined effects of diabetes and pharmacological interventions with dapagliflozin or liraglutide on bone strength at the femur midshaft (Table 1). Interestingly, at the whole-bone level, compared to lean animals, diabetic+saline mice presented with significant reductions in ultimate displacement $(40 \%$, $\mathrm{p}=0.023)$, post-yield displacement $(57 \%, \mathrm{p}=0.012)$, post-yield work $(43 \%, \mathrm{p}=0.027)$ and work to fracture $(34 \%, p=0.037)$. None of the other biomechanical parameters were significantly altered in saline-treated animals. Despite trends in enhancing ultimate displacement, post-yield displacement, post-yield work and work to fracture, none of dapagliflozin or liraglutide significantly ameliorated these parameters. At 
the tissue level, ultimate strain $(39 \%, p=0.039)$ and post-yield strain $(56 \%, p=0.021)$ were significantly lower in saline-treated animals as compared with lean+saline mice. Here again, dapagliflozin and liraglutide, although despite slight enhancement, did not significantly improved these parameters.

\subsection{Type 2 diabetes mellitus or short-term treatment with dapagliflozin or liraglutide did not significantly alter bone microarchitecture}

In order to understand if changes in bone microarchitecture could account for the observed modifications of bone strength at the whole-bone levels, we investigated trabecular and cortical bone structure in femurs by microCT. Interestingly, cortical and trabecular bone microarchitectures were not different in diabetic+saline animals compared to lean controls (Figures 2A-B). Dapagliflozin- and liraglutide-treated mice presented with similar cortical and trabecular bone microarchitectures as diabetic+saline or lean+saline animals (Figures 2A-B).

Furthermore, as SGLT2 inhibitors have been suspected to induce secondary hyperparathyroidism, we quantified osteoid surfaces and thickness by conventional histology. However, none of these two parameters were altered by diabetes or pharmacological intervention. Although freezing is not usually recommended for preserving morphological features of bone cells, the number of osteoclasts and osteoblasts have been quantified in TRAP-stained or toluidine blue-stained sections. Supplementary Figure 2 provides representative image of stained sections. Numbers of osteoblasts and osteoclasts were not significantly different between the four groups of animals (Figure 2B). No differences in the mineral apposition rate, mineralizing surface and bone formation rate were observed between the four groups of animals.

\subsection{Dapagliflozin and liraglutide ameliorated bone tissue material properties and bone matrix} strength at bone formation site

In order to determine the contribution of bone matrix composition in bone strength, we investigated several bone parameters over the full cortical width by Fourier transform infrared imaging (Figure 3AB). As compared with lean+saline animals, diabetic+saline mice presented with significant lower mean phosphate/amide $(10 \%, p=0.037)$ and collagen maturity $(10 \%, p<0.001)$, and higher mean tissue water content $(38 \%, p=0.002)$, crystal size index $(21 \%, p=0.010)$ and collagen glycation $(86 \%, p=0.028)$. Distribution heterogeneity in all investigated parameters were similar between all groups of animals 
(Supplementary Figure 3). Interestingly, the normalized collagen crosslinks distribution highlighted a significant reduction in immature and an increase in mature collagen crosslinks, suggesting faster maturation of the former. None of the two pharmacological interventions significantly changed these bone parameters despite trends of improvement.

However, with respect to the bone formation rate observed in the present study, we could estimate that only $\approx 5 \%$ of the cortical width has been formed during the use of dapagliflozin or liraglutide (28-day treatment). With this in mind, we decided to investigate bone matrix composition at bone formation site to decipher the effects of SGLT2i and GLP-1RA on bone material properties.

Supplementary Figure 4A presents mean Fourier infrared spectra for the four groups of animals at bone formation site. A broadening at 1100-1150 cm-1 was observed in diabetic+saline animals. This spectral region is representative of phosphate in poorly mature mineral (Supplementary Table 1). Diabetic+saline mice presented with significant lower phosphate/amide $(19 \%, p<0.001)$ and carbonate/phosphate ratio $(14 \%, p<0.001)$ and with higher tissue water content $(96 \%, p<0.001)$ (Figure $3 C)$. Interestingly, dapagliflozin and liraglutide significantly increased the phosphate/amide ratio to similar extent. However, despite both molecules decreased tissue water content (Figure $3 \mathrm{C}$ ), the extent of this reduction was greater with dapagliflozin ( $64 \%$ vs. $43 \%, p=0.011)$.

We next performed second derivative and curve fitting of the v1,v3 phosphate band (Supplementary Figure 4B). Surprisingly, the $1020 \mathrm{~cm}^{-1}$ subpeaks, corresponding to phosphate vibration in nonstoichiometric apatite, and routinely used for the computation of mineral crystallinity, was not evidenced in diabetic animals albeit of their treatment. However, the $1030 \mathrm{~cm}^{-1}$ subpeak, indicative of phosphate vibration in apatitic environment and the $1110 \mathrm{~cm}^{-1}$ subpeak, indicative of phosphate vibration in nonstoichiometric apatite, were clearly evidenced. We then chose the validated 1030/1110 $\mathrm{cm}^{-1}$ ratio as a measure of mineral maturity. Mineral maturity ratio was decreased without reaching statistical significance $(p=0.085)$ in diabetic+saline animals (Figure $3 C)$. However, crystal size index, that augments with crystal size in the 002, 211, 200 and 202 directions [16], was significantly elevated by $41 \%$ in saline-treated diabetic animals $(\mathrm{p}=0.001)$. Interestingly, dapagliflozin administration resulted in significant higher mineral maturity ratio $(60 \%, p=0.007)$ and lower crystal size index $(35 \%, p<0.001)$. On the other hand, liraglutide administration resulted in only significant lower crystal size index (41\%, $\mathrm{p}<0.001)$ 
In order to investigate change in the organic phase of the bone matrix, we also computed the second derivative curve of the amide I-II bands followed by curve fitting (Supplementary Figure 4C). Salinetreated diabetic mice presented with significant lower amount of mature collagen crosslinks (64\%, $p<0.001)$ and collagen maturity ( $52 \%, p<0.001)$, and higher collagen glycation (454\%, $p<0.001)$ (Figure 3D). Administration of dapagliflozin resulted in significant higher mature and immature collagen crosslinks (38\%, $p=0.002$ and $38 \%, p=0.010$, respectively) and lower collagen glycation $(55 \%, p<0.001)$ as compared with saline-treated diabetic mice. Administration of liraglutide led to significant higher mature collagen crosslinks $(138 \%, p<0.001)$ and collagen maturity $(107 \%, p<0.001)$ and lower collagen glycation $(56 \%, p<0.001)$. We also computed the normalized amount of immature and mature collagen crosslinks (Figure 3D). Saline-treated diabetic animals presented with higher immature and lower mature normalized collagen crosslinks ( $p<0.001$ and $p<0.001$, respectively), suggesting a reduction in post-processing of collagen molecules. Interestingly, liraglutide, but not dapagliflozin, was capable of restoring a normal post-processing of collagen molecules.

\subsection{Dapagliflozin and liraglutide ameliorated matrix biomechanics at bone formation site}

Biomechanical properties of the newly formed bone matrix were investigated by nanoindentation between double calcein labelling (Table 2). Diabetic+saline animals exhibited significant reductions in hardness $(40 \%, p<0.001)$, indentation modulus $(34 \%, p<0.001)$, maximum load $(35 \%, p<0.001)$ and work of indentation $(34 \%, p<0.001)$. Dapagliflozin administration led to significant higher values of hardness $(49 \%, p=0.001)$, indentation modulus $(31 \%, p<0.001)$, maximum load $(43 \%, p<0.001)$ and work of indentation $(52 \%, p<0.001)$. Administration of liraglutide had similar effects with higher hardness (39\%, $\mathrm{p}=0.002)$, indentation modulus $(18 \%, \mathrm{p}=0.015)$, maximum load $(29 \%, \mathrm{p}<0.001)$ and work of indentation $(28 \%, \mathrm{p}=0.003)$. However, it is worth noting that the extent of augmentation in the work of indentation was significantly greater with dapagliflozin as compared with liraglutide $(p=0.008)$.

\section{DISCUSSION}

Type 2 diabetes mellitus (T2DM) is associated with higher risk of fracture that is greater than would be predicted by bone mineral density, suggesting alterations of bone quality. Among all the parameters that account for bone quality, bone material properties represent the first hierarchical organization of bone that in essence is independent of macro- and microstructure. In the present study, we clearly 
demonstrated that newly formed bone presented with a lower bone strength at the material level in diabetic animals as compared with lean animals. Reduction in bone strength were linked to modifications in bone material properties (tissue water content, phosphate/amide ratio, crystal size index, collagen maturity and collagen glycation) independently of effects on bone remodelling or bone microarchitecture. It is worth noting that although a short treatment period could be perceived as a weakness, it was chosen as (1), in previous animal models of type 2 diabetes, 28 days of administration was enough to exhibit changes at the bone material properties and (2) we wanted to evidence whether these changes occurred before changes in bone remodelling or bone microstructure were evident.

The bone matrix is made of (1) an organic layer ( -35 to $45 \%$ by volume), composed mainly by fibrillar type I collagen with enzymatic and non-enzymatic crosslinks, (2) a mineral phase ( $\sim 35$ to $45 \%$ by volume), composed of calcium phosphate in the form of poorly crystalline hydroxyapatite with carbonate and various vacancies and (3) water ( 15 to $25 \%$ by volume) [21]. In the matrix, water exists in two states, free water, found in intracortical porosity, including the lacuno-canalicular network and voids between microfibrils, and bound water associated to hydrophilic residue of type I collagen and proteoglycan in the organic phase as well as crystal surface where it orients apatite crystals during biomineralization. Tissue water content decreases with the mineralization process when apatite crystals fill voids between type I collagen fibrils [22]. Vibrational determination of tissue water content takes advantage of water replacement during chemical dehydration and pMMA impregnation during the embedding process. Subsequently, tissue water content corresponds to free water, but also loosely bound water molecules. To the best of our knowledge, vibrational determination of tissue water content, as used in the present study, has never been compared head-to-head with UTE-MRI or thermogravimetric techniques. However, it is worth noting that bound water volume fraction, measured by UTE-MRI, was shown inversely correlated with tissue mineral density and ageing in rodents and humans $[23,24]$. Similar observations have previously been observed with vibrational determination of tissue water content $[15,25]$.

In the present study, we evidenced that diabetes led to alterations of the three main components of the bone matrix that ultimately led to changes in mechanical behaviour at the material scale. The reason for higher tissue water content in diabetic bone matrix is unknown at the present. In intervertebral disks, the amount of advanced glycation end-products have been inversely correlated to the tissue water content 
[26]. However, whether a similar correlation exists for bone remains to be investigated. In the present study, higher collagen glycation was observed in the presence of higher tissue water content. Lower phosphate/amide ratio, in addition to higher tissue water content, suggest that accumulation of apatite crystals is lower in diabetes and that the propensity of voids in the bone matrix is higher. This is in agreement with the reduction in hardness and indentation modulus measured by nanoindentation. With respect to the role of water in controlling apatite orientation and growth during biomineralization, it is not surprising to evidence changes in crystal size (bigger crystal as evidenced by higher crystal size index) suggesting of possible phase and compositional modifications. Alterations of crystal size have previously been associated with bone fragility [27]. Diabetes led also to abnormal collagen postprocessing with lower maturation of immature divalent collagen crosslinks to mature trivalent crosslinks. Interestingly dapagliflozin and liraglutide restored mineral parameters, and hence accumulation of apatite crystals into the bone matrix, in levels comparable to non-diabetic animals. However, only liraglutide, restored normal post-processing of type I collagen molecule suggesting that action outside of glycemic controls, are important for normal collagen physiology.

Our present study, with a short duration of diabetes induction and treatment, highlighted that compromised bone strength is a rapid process in type 2 diabetes mellitus and primarily due to rapid alterations of bone material properties independently of changes in bone remodelling or bone microarchitecture. Bone cell fate and activities are regulated by several extracellular signals including matrix biomechanics. Matrix stiffness is an important modulator of bone cell activities with low matrix stiffness reducing osteoblast differentiation and bone formation [28]. Indeed, mesenchymal stem cells and osteoblasts, through membrane-expressed integrins, Piezo1/2 excitatory ion channels and cytoskeleton-associated protein sense changes in matrix stiffness and adapt their transcriptional activity by nuclear translocation of transcriptional coactivator with PDZ-binding motif (TAZ) and its paralog Yes associated protein (YAP) as well as MAPK and Wnt activation [29-32]. In the bone-diabetes field, it is well accepted that chronic hyperglycaemia, through the formation of advanced glycation end-products, reduce osteoblast and osteoclast activities [33-35]. However, in light with the important emerging role of matrix stiffness on cell activity, the undisputed effects of diabetes on bone material properties and hence matrix biomechanics and the kinetic of material properties alterations, changes in bone material properties not only contribute to reduced bone toughness, but also might be a signal triggering lower 
bone cell activity in long-term uncontrolled diabetes. Figure 4 proposes a schematic of the perturbations leading to reduced bone strength in diabetes. Further studies are required to ascertain the role of local matrix stiffness changes on bone cell differentiation and function in diabetes.

Despite trends, dapagliflozin and liraglutide failed to significantly improved bone strength at the wholebone levels. This was further confirmed by the lack of significant effects, again despite trends, on bone material properties when analyses were performed on the full cortical width. This is probably due to the low amount of cortical bone formed during pharmacological intervention. Indeed, based on bone formation rate evidenced in the present study, we estimated the amount of cortical bone build during the study at $\sim 5 \%$. However, when analyses were performed only at bone formation site, modulation of several bone material properties were evident with both molecules as well as modulation of matrix biomechanics. This is interesting and suggest that dapagliflozin and liraglutide do not modify the characteristic of bone formed before treatment. However, it would be interesting to assess whether the improvement in bone material properties observed with dapagliflozin and liraglutide persist when the bone matrix maturates. No effects of both dapagliflozin and liraglutide have been evidenced on either bone formation rate or osteoid parameter. However, it is worth noting that although not significant, osteoid surface and thickness had a trend to higher values in dapagliflozin- or liraglutide-treated animals and could also support the role of ameliorated matrix biomechanics and reduced advanced glycation end-products on bone formation.

Although beneficial effects of liraglutide could have been envisaged based on previous published literature with GLP-1RAs [11, 36-38], the positive effects of dapagliflozin on bone, or more generally SGLT2i, were still the subject of some discussion. Long term studies of patients with T2DM and moderate impairment and/or prior risk/history of cardiovascular diseases reported a small but significant increase in treatment-emergent bone fractures with dapagliflozin and canagliflozin [7, 8]. Conflicting biomarker data suggests that canagliflozin increases bone turnover and reduces bone mineral density at the total hip [39], whereas dapagliflozin does not seem to affect any of these parameters [40]. One possible explanation for the discrepancy may reside in the dose that led to maximum inhibition of endogenous SGLT2 as the approved $10 \mathrm{mg}$ dose of dapagliflozin results in approximately $65 \%$ inhibition while $300 \mathrm{mg}$ dose of canagliflozin leads to full inhibition [41, 42]. To follow this idea, in the present study 
we used a dose of $1 \mathrm{mg} / \mathrm{kg} /$ day equivalent to a dose of $\sim 100 \mathrm{mg} /$ day for adult T2DM patients. However, we failed to demonstrate any detrimental effects of dapagliflozin on bone health and on the contrary we evidenced improvement in bone composition parameters at bone formation site.

Several hypotheses had previously been formulated to explain the higher rate of fractures observed with SGLT2i, covering the spectrum of maintenance of sodium homeostasis to secondary hyperparathyroidism. We previously reported that in response to SGLT2i, compensatory mechanisms are observed in the primary convoluted tubule and represented by higher expression of other $\mathrm{Na}$ transporters, namely NaPi-2a and NHE3 [43]. Recently, Blau and colleagues proposed that SGLT2i therapy results in higher levels of serum phosphorus and plasma FGF-23 and lower concentrations of 1,25-dihydrovitamin $\mathrm{D}$ [44]. These changes are thought to trigger secondary hyperparathyroidism. However, it is worth noting that when hyperparathyroidism is concomitant with vitamin D deficiency, as proposed by Blau and colleagues, the pattern of histomorphometrical features might be altered dramatically ranging from high to low bone turnover. However, although we did not measure plasma PTH as we did not withdraw enough blood for such evaluation, in response to dapagliflozin, we did not evidence any modifications of bone microarchitecture or histomorphometrical features (osteoid parameter, number of osteoblasts or osteoclasts, bone formation rate) usually observed in cases of hyperparathyroidism. Furthermore, dapagliflozin-treated animals exhibited the same panel of histomorphometrical features as noted with liraglutide treatment. In light of the lack of data on hyperparathyroidism and vitamin D deficiency in previous studies with liraglutide, it is unlikely that this mechanism occurred in our study. Strengthening this view is the lack of significant increase in PTH and FGF-23 concentrations in canagliflozin-treated diabetic mice that has been reported previously [45].

Thrailkill and colleagues, and in opposition to what we observed in the present study, reported previously ameliorations of bone biomechanics, including higher post-yield displacement and work-to-fracture, with canagliflozin in streptozotocin-injected diabetic DBA/2J mice [46]. These positive changes were linked to changes in bone microarchitecture, but it is worth noting that bone material properties have not been investigated by Thrailkill et al. This might appear controversial with our study, but it is worth noting that: (1) canagliflozin was administered for 10 weeks whereas dapagliflozin was only given for 4 weeks in our study; and (2) the STZ-DBA/2J mouse model is a type 1 diabetic model with compromised insulin 
secretion rather than a type 2 diabetic mouse model as proposed for STZ-high fat fed mice. Supporting our data, Suzuki and colleagues were also unable to observe changes in bone mass following 9 weeks of Tofogliflozin, another SGLT2 inhibitor, in type 2 diabetic male KKAy rats [47]. Whether changes in bone microarchitecture observed in Thraikill et al. is due exclusively to canagliflozin will need further investigations in the future. In agreement with our study, recent meta-analyses of randomized clinical trials, population-based open cohort and national register-based studies failed to evidence any negative effects of SGLT2i on bone health in the diabetic population [48-50].

In a previous head-to-head comparison between dapagliflozin and liraglutide, we demonstrated that both molecules led to similar extent in amelioration of blood glucose level (fasted and non-fasted), HbA1c and HOMA-IR [51]. This is interesting with respect to the different modes of action of these molecules. Dapagliflozin enhances urinary glucose excretion by inhibiting the function of the renal sodium-glucose contransporter-2 in the early proximal convoluted tubule. Although actions of dapagliflozin appear to be independent of insulin secretion, it improves insulin sensitivity, most likely as a result of sustained reduction in hyperglycaemia, alleviation of glucose toxicity and weight reduction through enhanced caloric loss $[9,52,53]$. On the other hand, liraglutide does not act on urinary glucose excretion but rather exhibits a range of beneficial actions represented by weight loss, induction of satiety, inhibition of gastric emptying, stimulation of insulin secretion and inhibition of alpha cell function [54]. Previously, we demonstrated that the most beneficial actions of GLP-1 receptor agonists on bone were mediated through amelioration of blood glucose level $[11,37]$. However, in the present study, despite similar effects on blood glucose level, several differences at the tissue level were evidenced between the two molecules suggesting that in addition to amelioration of blood glucose level, these two molecules exert other actions to modulate bone material properties. As SGLT2 or the classical GLP-1 receptor is not expressed in bone $[46,55]$, modulation of bone material properties is probably indirect and will need to be further deciphered in the future.

In conclusion, the present study highlighted that dapagliflozin and liraglutide treatment were capable of reversing some of the detrimental effects of diabetes on bone material properties and matrix biomechanics at bone formation site. This sheds new light on the choice of glucose-lowering agents in 
diabetes in order to reduce the risk of bone fracture with high effects on metabolic parameters. Further studies will need to be conducted in humans to fully validate these findings.

\section{ACKNOWLEDGEMENTS}

The authors are grateful to Nadine Gaborit and Stéphanie Lemière (University of Angers, GEROMLHEA, Institut de Biologie en Santé, Angers, France) for their help with microCT.

\section{CONFLICT OF INTEREST}

A. Mieczkowska, P. Millar, D. Chappard, V.A. Gault and G. Mabilleau have no conflict of interest to report

\section{AUTHOR CONTRIBUTIONS}

A.M., and P.M. conducted the experiments and collected all data. D.C., V.A.G. and G.M. analysed the data. V.A.G and G.M. wrote the manuscript. All authors have reviewed and approved the manuscript.

\section{REFERENCES}

1. Federation ID (2017) IDF Diabetes Atlas - 8th edition.

2. Napoli N, Chandran M, Pierroz DD, Abrahamsen B, Schwartz AV, Ferrari SL, Bone IOF, Diabetes Working G (2017) Mechanisms of diabetes mellitus-induced bone fragility. Nat Rev Endocrinol 13:208-219

3. Hamann C, Kirschner S, Gunther KP, Hofbauer LC (2012) Bone, sweet bone--osteoporotic fractures in diabetes mellitus. Nat Rev Endocrinol 8:297-305

4. Mieczkowska A, Basle MF, Chappard D, Mabilleau G (2012) Thiazolidinediones induce osteocyte apoptosis by a $\mathrm{G}$ protein-coupled receptor 40-dependent mechanism. J Biol Chem 287:23517-23526

5. Tahrani AA, Barnett AH, Bailey CJ (2016) Pharmacology and therapeutic implications of current drugs for type 2 diabetes mellitus. Nat Rev Endocrinol 12:566-592

6. Bailey CJ, Marx N (2019) Cardiovascular protection in type 2 diabetes: Insights from recent outcome trials. Diabetes Obes Metab 21:3-14

7. Kohan DE, Fioretto P, Tang W, List JF (2014) Long-term study of patients with type 2 diabetes and moderate renal impairment shows that dapagliflozin reduces weight and blood pressure but does not improve glycemic control. Kidney Int 85:962-971

8. Watts NB, Bilezikian JP, Usiskin K, Edwards R, Desai M, Law G, Meininger G (2016) Effects of Canagliflozin on Fracture Risk in Patients With Type 2 Diabetes Mellitus. J Clin Endocrinol Metab 101:157-166

9. Millar PJ, Pathak V, Moffett RC, Pathak NM, Bjourson AJ, O'Kane MJ, Flatt PR, Gault VA (2016) Beneficial metabolic actions of a stable GIP agonist following pre-treatment with a SGLT2 inhibitor in high fat fed diabetic mice. Mol Cell Endocrinol 420:37-45 
10. Moffett RC, Patterson S, Irwin N, Flatt PR (2015) Positive effects of GLP-1 receptor activation with liraglutide on pancreatic islet morphology and metabolic control in C57BL/KsJ db/db mice with degenerative diabetes. Diabetes Metab Res Rev 31:248-255

11. Pereira M, Gohin S, Roux JP, Fisher A, Cleasby ME, Mabilleau G, Chenu C (2017) Exenatide Improves Bone Quality in a Murine Model of Genetically Inherited Type 2 Diabetes Mellitus. Front Endocrinol (Lausanne) 8:327

12. Flatt PR, Bailey CJ (1981) Development of glucose intolerance and impaired plasma insulin response to glucose in obese hyperglycaemic (ob/ob) mice. Horm Metab Res 13:556-560

13. Bouxsein ML, Boyd SK, Christiansen BA, Guldberg RE, Jepsen KJ, Muller R (2010) Guidelines for assessment of bone microstructure in rodents using micro-computed tomography. J Bone Miner Res 25:1468-1486

14. Dempster DW, Compston JE, Drezner MK, Glorieux FH, Kanis JA, Malluche H, Meunier PJ, Ott SM, Recker RR, Parfitt AM (2013) Standardized nomenclature, symbols, and units for bone histomorphometry: a 2012 update of the report of the ASBMR Histomorphometry Nomenclature Committee. J Bone Miner Res 28:2-17

15. Paschalis EP, Fratzl P, Gamsjaeger S, Hassler N, Brozek W, Eriksen EF, Rauch F, Glorieux FH, Shane E, Dempster D, Cohen A, Recker R, Klaushofer K (2016) Aging Versus Postmenopausal Osteoporosis: Bone Composition and Maturation Kinetics at Actively-Forming Trabecular Surfaces of Female Subjects Aged 1 to 84 Years. J Bone Miner Res 31:347-357

16. Gadaleta SJ, Paschalis EP, Betts F, Mendelsohn R, Boskey AL (1996) Fourier transform infrared spectroscopy of the solution-mediated conversion of amorphous calcium phosphate to hydroxyapatite: new correlations between X-ray diffraction and infrared data. Calcif Tissue Int 58:9-16

17. Gobron B, Bouvard B, Legrand E, Chappard D, Mabilleau G (2020) GLP-2 administration in ovariectomized mice enhances collagen maturity but did not improve bone strength. Bone Rep 12:100251

18. Mieczkowska A, Mansur SA, Irwin N, Flatt PR, Chappard D, Mabilleau G (2015) Alteration of the bone tissue material properties in type 1 diabetes mellitus: A Fourier transform infrared microspectroscopy study. Bone 76:31-39

19. Ou-Yang H, Paschalis EP, Mayo WE, Boskey AL, Mendelsohn R (2001) Infrared microscopic imaging of bone: spatial distribution of CO3(2-). J Bone Miner Res 16:893-900

20. Oliver WC, Pharr GM (1992) An improved technique for determining hardness and elastic modulus using load and displacement sensing indentation experiments. J Mater Res 7:15641583

21. Mueller KH, Trias A, Ray RD (1966) Bone density and compostiton. Age-related and pathological changes in water and mineral content. J Bone Joint Surg Am 48:140-148

22. Robinson RA (1975) Physiocochemical structure of bone. Clin Orthop Relat Res:263-315

23. Currey JD, Brear K, Zioupos P (1996) The effects of ageing and changes in mineral content in degrading the toughness of human femora. J Biomech 29:257-260

24. Granke M, Does MD, Nyman JS (2015) The Role of Water Compartments in the Material Properties of Cortical Bone. Calcif Tissue Int 97:292-307

25. Paschalis EP, Gamsjaeger S, Fratzl-Zelman N, Roschger P, Masic A, Brozek W, Hassler N, Glorieux FH, Rauch F, Klaushofer K, Fratzl P (2016) Evidence for a Role for Nanoporosity and Pyridinoline Content in Human Mild Osteogenesis Imperfecta. J Bone Miner Res 31:1050-1059

26. Jazini E, Sharan AD, Morse L, Dyke JP, Aronowitz EB, Chen LK, Tang SY (2012) Alterations in T2 relaxation magnetic resonance imaging of the ovine intervertebral disc due to nonenzymatic glycation. Spine (Phila Pa 1976) 37:E209-215

27. Milovanovic P, Rakocevic Z, Djonic D, Zivkovic V, Hahn M, Nikolic S, Amling M, Busse B, Djuric $M$ (2014) Nano-structural, compositional and micro-architectural signs of cortical bone fragility at the superolateral femoral neck in elderly hip fracture patients vs. healthy aged controls. Exp Gerontol 55:19-28 
28. Engler AJ, Sen S, Sweeney HL, Discher DE (2006) Matrix elasticity directs stem cell lineage specification. Cell 126:677-689

29. Shih YR, Tseng KF, Lai HY, Lin CH, Lee OK (2011) Matrix stiffness regulation of integrin-mediated mechanotransduction during osteogenic differentiation of human mesenchymal stem cells. J Bone Miner Res 26:730-738

30. Zhang T, Lin S, Shao X, Zhang Q, Xue C, Zhang S, Lin Y, Zhu B, Cai X (2017) Effect of matrix stiffness on osteoblast functionalization. Cell Prolif 50

31. Hwang JH, Byun MR, Kim AR, Kim KM, Cho HJ, Lee YH, Kim J, Jeong MG, Hwang ES, Hong JH (2015) Extracellular Matrix Stiffness Regulates Osteogenic Differentiation through MAPK Activation. PLoS One 10:e0135519

32. Zhou T, Gao B, Fan Y, Liu Y, Feng S, Cong Q, Zhang X, Zhou Y, Yadav PS, Lin J, Wu N, Zhao L, Huang D, Zhou S, Su P, Yang Y (2020) Piezo1/2 mediate mechanotransduction essential for bone formation through concerted activation of NFAT-YAP1-ss-catenin. Elife 9

33. McCarthy AD, Uemura T, Etcheverry SB, Cortizo AM (2004) Advanced glycation endproducts interefere with integrin-mediated osteoblastic attachment to a type-I collagen matrix. Int J Biochem Cell Biol 36:840-848

34. Sanguineti R, Storace D, Monacelli F, Federici A, Odetti P (2008) Pentosidine effects on human osteoblasts in vitro. Ann N Y Acad Sci 1126:166-172

35. Valcourt U, Merle B, Gineyts E, Viguet-Carrin S, Delmas PD, Garnero P (2007) Non-enzymatic glycation of bone collagen modifies osteoclastic activity and differentiation. J Biol Chem 282:5691-5703

36. Kim JY, Lee SK, Jo KJ, Song DY, Lim DM, Park KY, Bonewald LF, Kim BJ (2013) Exendin-4 increases bone mineral density in type 2 diabetic OLETF rats potentially through the down-regulation of SOST/sclerostin in osteocytes. Life Sci 92:533-540

37. Mansur SA, Mieczkowska A, Flatt PR, Chappard D, Irwin N, Mabilleau G (2019) The GLP-1 Receptor Agonist Exenatide Ameliorates Bone Composition and Tissue Material Properties in High Fat Fed Diabetic Mice. Front Endocrinol (Lausanne) 10:51

38. Sun HX, Lu N, Luo X, Zhao L, Liu JM (2015) Liraglutide, the glucagon-like peptide-1 receptor agonist, has anabolic bone effects in diabetic Goto-Kakizaki rats. J Diabetes 7:584-588

39. Bilezikian JP, Watts NB, Usiskin K, Polidori D, Fung A, Sullivan D, Rosenthal N (2016) Evaluation of Bone Mineral Density and Bone Biomarkers in Patients With Type 2 Diabetes Treated With Canagliflozin. J Clin Endocrinol Metab 101:44-51

40. Ljunggren O, Bolinder J, Johansson L, Wilding J, Langkilde AM, Sjostrom CD, Sugg J, Parikh S (2012) Dapagliflozin has no effect on markers of bone formation and resorption or bone mineral density in patients with inadequately controlled type 2 diabetes mellitus on metformin. Diabetes Obes Metab 14:990-999

41. Komoroski B, Vachharajani N, Boulton D, Kornhauser D, Geraldes M, Li L, Pfister M (2009) Dapagliflozin, a novel SGLT2 inhibitor, induces dose-dependent glucosuria in healthy subjects. Clin Pharmacol Ther 85:520-526

42. Taylor SI, Blau JE, Rother KI (2015) Possible adverse effects of SGLT2 inhibitors on bone. Lancet Diabetes Endocrinol 3:8-10

43. Ma C, de Baaij JHF, Millar PJ, Gault VA, de Galan BE, Bindels RJM, Hoenderop JGJ (2019) Effect of Dapagliflozin Treatment on the Expression of Renal Sodium Transporters/Channels on HighFat Diet Diabetic Mice. Nephron 142:51-60

44. Blau JE, Bauman V, Conway EM, Piaggi P, Walter MF, Wright EC, Bernstein S, Courville AB, Collins MT, Rother KI, Taylor SI (2018) Canagliflozin triggers the FGF23/1,25-dihydroxyvitamin D/PTH axis in healthy volunteers in a randomized crossover study. JCI Insight 3

45. Thrailkill KM, Clay Bunn R, Nyman JS, Rettiganti MR, Cockrell GE, Wahl EC, Uppuganti S, Lumpkin CK, Jr., Fowlkes JL (2016) SGLT2 inhibitor therapy improves blood glucose but does not prevent diabetic bone disease in diabetic DBA/2J male mice. Bone 82:101-107 
46. Thrailkill KM, Nyman JS, Bunn RC, Uppuganti S, Thompson KL, Lumpkin CK, Jr., Kalaitzoglou E, Fowlkes JL (2017) The impact of SGLT2 inhibitors, compared with insulin, on diabetic bone disease in a mouse model of type 1 diabetes. Bone 94:141-151

47. Suzuki M, Takeda M, Kito A, Fukazawa M, Yata T, Yamamoto M, Nagata T, Fukuzawa T, Yamane M, Honda K, Suzuki Y, Kawabe Y (2014) Tofogliflozin, a sodium/glucose cotransporter 2 inhibitor, attenuates body weight gain and fat accumulation in diabetic and obese animal models. Nutr Diabetes 4:e125

48. Kohler S, Kaspers S, Salsali A, Zeller C, Woerle HJ (2018) Analysis of Fractures in Patients With Type 2 Diabetes Treated With Empagliflozin in Pooled Data From Placebo-Controlled Trials and a Head-to-Head Study Versus Glimepiride. Diabetes Care 41:1809-1816

49. Tang HL, Li DD, Zhang JJ, Hsu YH, Wang TS, Zhai SD, Song YQ (2016) Lack of evidence for a harmful effect of sodium-glucose co-transporter 2 (SGLT2) inhibitors on fracture risk among type 2 diabetes patients: a network and cumulative meta-analysis of randomized controlled trials. Diabetes Obes Metab 18:1199-1206

50. Toulis KA, Bilezikian JP, Thomas GN, Hanif W, Kotsa K, Thayakaran R, Keerthy D, Tahrani AA, Nirantharakumar K (2018) Initiation of dapagliflozin and treatment-emergent fractures. Diabetes Obes Metab 20:1070-1074

51. Millar P, Pathak N, Parthsarathy V, Bjourson AJ, O'Kane M, Pathak V, Moffett RC, Flatt PR, Gault VA (2017) Metabolic and neuroprotective effects of dapagliflozin and liraglutide in diabetic mice. J Endocrinol 234:255-267

52. Macdonald FR, Peel JE, Jones HB, Mayers RM, Westgate L, Whaley JM, Poucher SM (2010) The novel sodium glucose transporter 2 inhibitor dapagliflozin sustains pancreatic function and preserves islet morphology in obese, diabetic rats. Diabetes Obes Metab 12:1004-1012

53. Merovci A, Mari A, Solis-Herrera C, Xiong J, Daniele G, Chavez-Velazquez A, Tripathy D, Urban McCarthy S, Abdul-Ghani M, DeFronzo RA (2015) Dapagliflozin lowers plasma glucose concentration and improves beta-cell function. J Clin Endocrinol Metab 100:1927-1932

54. Bailey CJ, Tahrani AA, Barnett AH (2016) Future glucose-lowering drugs for type 2 diabetes. Lancet Diabetes Endocrinol 4:350-359

55. Pereira M, Jeyabalan J, Jorgensen CS, Hopkinson M, Al-Jazzar A, Roux JP, Chavassieux P, Orriss IR, Cleasby ME, Chenu C (2015) Chronic administration of Glucagon-like peptide-1 receptor agonists improves trabecular bone mass and architecture in ovariectomised mice. Bone 81:459-467 


\section{FIGURE LEGENDS}

Figure 1: Effects of once-daily dapagliflozin or liraglutide on metabolic parameters. (A) Blood glucose was measured over the 28-day period at the apex of the tail vein in conscious mice. Glucose area under the curve (AUC) are shown. (B) Glucose tolerance and (C) insulin response to glucose at the end of the study. Glucose and insulin concentrations were measured prior to and after oral administration of glucose $(18 \mathrm{mmol} / \mathrm{kg})$ in 12-h fasted mice. Glucose and insulin AUC values post injection are also shown. (D) Glucose response to insulin measured at the end of the study period. Glucose concentrations were measured prior to and after injection of insulin ( $25 \mathrm{U} / \mathrm{kg}$; i.p.) in non-fasted mice. Glucose area above the curve (AAC) values post injection are also shown. Values are means \pm SD for 8 mice/group. *: $p<0.05$ vs. diabetic+saline.

Figure 2: Effects of once-daily dapagliflozin or liraglutide on bone microarchitecture. (A) Cortical bone microarchitecture and (B) trabecular bone microarchitecture by high-resolution X-ray tomography and bone histomorphometry. Tt.Ar: total tissue area, Ma.Ar: marrow area, Ct.Th: cortical thickness, Ct.Po: cortical porosity, BV/TV: trabecular bone volume, Tb.N: trabecular number, Tb.Th: trabecular thickness, Tb.Sp: trabecular spacing, OS/BS: osteoid surface, O.Th: osteoid thickness, N.Oc/B.Pm: number of osteoclasts and N.Ob/B.Pm: number of osteoblasts. Values are means \pm SD for 8 mice. *: $p<0.05$ vs. diabetic + saline.

Figure 3: Effects of once daily dapagliflozin and liraglutide on bone material properties over the full cortical width and at bone formation site. Bone material properties were investigated by Fourier transform infrared imaging (FTIRI) (A-B) in the posterior quadrant and by Fourier transform infrared microspectroscopy (FTIRM) (C-D) at site of bone formation. For each FTIRI parameter, only the mean distribution has been reported. Normalized enzymatic collagen crosslinks $(\mathrm{XL})$ have been computed as the percentage of total crosslinks. Lean+saline (Black bars), diabetic+saline (white bars), diabetic+dapagliflozin (light grey bars) and diabetic+liraglutide (dark grey bars). Values are means \pm SD for 8 mice. *: $p<0.05$ vs. diabetic+saline, $\$: p<0.05$ vs. diabetic+dapagliflozin.

Figure 4: Schematic of bone changes with type 2 diabetes mellitus and dapagliflozin or liraglutide administration. Alteration of glucose metabolism leads to a chronic hyperglycaemia state and the generation of advanced glycation end-products (AGE). AGE target bone cells activities that 
ultimately, in the long-term, lead to alterations in bone mass, microarchitecture and bone material properties reducing bone strength. In the present study, parameters affected by dapagliflozin or liraglutide have been highlighted in italic. Short-term administration of both pharmacological interventions led to significant improvement of chronic hyperglycaemia, bone material properties and matrix biomechanics. 


\section{TABLES}

Table 1: Biomechanical assessment at the midshaft femur. Whole-bone mechanical properties have been deduced from load-displacement curves. Tissue-level mechanical properties have been calculated from beam theory equations. *: $p<0.05$ vs. diabetic+saline. Values are mean \pm SD of 8 mice/group.

\begin{tabular}{lcccc}
\hline \multicolumn{4}{c}{ Lean } & \multicolumn{3}{c}{ Diabetic } \\
\hline \multicolumn{1}{l}{ Treatment } & Saline & Saline & Dapagliflozin & Liraglutide \\
\hline Whole-bone mechanical properties & $19.7 \pm 3.3$ & $21.1 \pm 3.0$ & $21.3 \pm 2.8$ & $21.8 \pm 3.3$ \\
Ultimate load (N) & $0.73 \pm 0.24^{\star}$ & $0.44 \pm 0.09$ & $0.59 \pm 0.24$ & $0.54 \pm 0.22$ \\
Ultimate displacement (mm) & $83.8 \pm 12.9$ & $89.1 \pm 20.3$ & $89.8 \pm 15.6$ & $99.5 \pm 17.4$ \\
Stiffness (N/mm) & $14.7 \pm 2.7$ & $16.2 \pm 2.2$ & $15.6 \pm 3.0$ & $15.8 \pm 4.1$ \\
Yield load (N) & $0.17 \pm 0.04$ & $0.20 \pm 0.05$ & $0.17 \pm 0.02$ & $0.16 \pm 0.03$ \\
Yield displacement (mm) & $0.56 \pm 0.23^{\star}$ & $0.24 \pm 0.09$ & $0.41 \pm 0.23$ & $0.38 \pm 0.25$ \\
Post-yield displacement (mm) & $1.4 \pm 0.6$ & $1.7 \pm 0.5$ & $1.4 \pm 0.4$ & $1.3 \pm 0.5$ \\
Pre-yield work (N.mm) & $7.6 \pm 2.6^{*}$ & $4.3 \pm 1.7$ & $6.8 \pm 2.5$ & $6.5 \pm 2.5$ \\
Post-yield work (N.mm) & $9.1 \pm 2.6^{\star}$ & $6.0 \pm 1.5$ & $8.3 \pm 2.7$ & $7.9 \pm 2.1$ \\
Work to fracture (N.mm) & & & \\
\hline Tissue-level mechanical properties & $155 \pm 26$ & $169 \pm 24$ & $148 \pm 19$ & $153 \pm 26$ \\
Ultimate stress (MPa) & $0.054 \pm 0.018^{*}$ & $0.033 \pm 0.007$ & $0.048 \pm 0.020$ & $0.043 \pm 0.018$ \\
Ultimate strain & $8.9 \pm 1.4$ & $9.5 \pm 2.2$ & $7.6 \pm 1.3$ & $8.6 \pm 1.5$ \\
Elastic modulus (GPa) & $116 \pm 21$ & $129 \pm 18$ & $109 \pm 21$ & $111 \pm 29$ \\
Yield stress (MPa) & $0.013 \pm 0.003$ & $0.015 \pm 0.004$ & $0.014 \pm 0.002$ & $0.013 \pm 0.003$ \\
Yield strain & $0.041 \pm 0.017^{*}$ & $0.018 \pm 0.007$ & $0.034 \pm 0.019$ & $0.031 \pm 0.020$ \\
Post-yield strain & & & & \\
\hline
\end{tabular}

Table 2: Biomechanical assessment at bone formation site. Matrix biomechanics were measured by nanoindentation between double calcein labelling. *: $p<0.05$ vs. diabetic+saline; $\$$ : $p<0.05$ vs. diabetic+dapagliflozin. Values are mean \pm SD of 8 mice/group.

\begin{tabular}{lcccc}
\hline & Lean & \multicolumn{3}{c}{ Diabetic } \\
\hline Treatment & Saline & Saline & Dapagliflozin & Liraglutide \\
\hline Hardness (MPa) & $822 \pm 46^{\star}$ & $493 \pm 72$ & $736 \pm 111^{*}$ & $683 \pm 57^{*}$ \\
Indentation modulus (GPa) & $15.8 \pm 1.0^{*}$ & $10.5 \pm 0.8$ & $13.8 \pm 1.1^{*}$ & $12.4 \pm 0.9^{*}$ \\
Maximum load (mN) & $13.9 \pm 0.1^{*}$ & $9.0 \pm 1.1$ & $12.9 \pm 0.9^{\star}$ & $11.6 \pm 1.2^{\star}$ \\
Work of indentation $(\mathrm{pJ})$ & $3237 \pm 149^{\star}$ & $2136 \pm 142$ & $3240 \pm 221^{*}$ & $2726 \pm 400^{*} \$$ \\
\hline
\end{tabular}



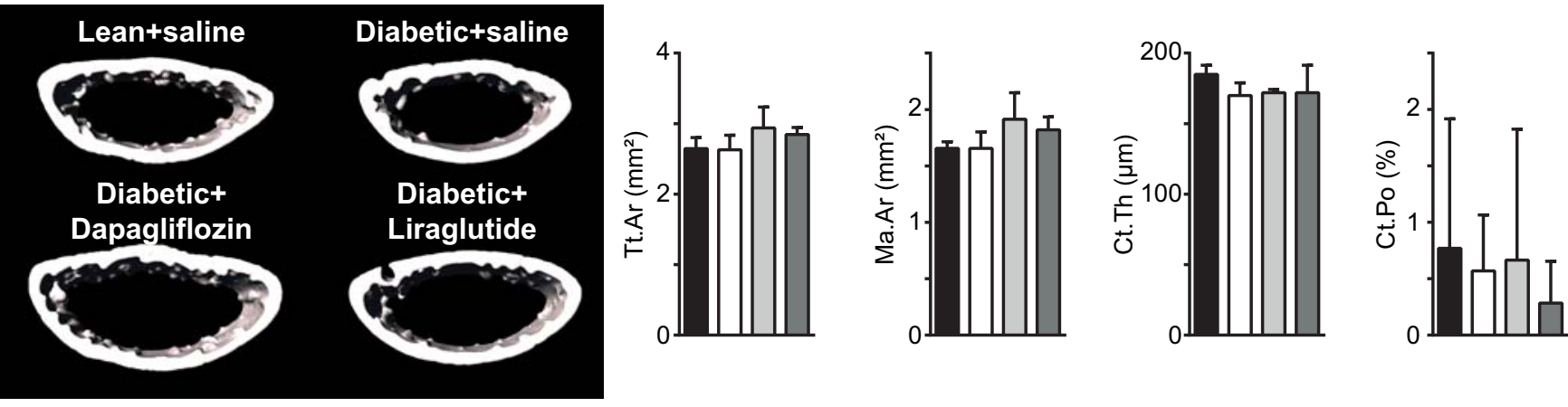

(B)

\section{Lean+saline}

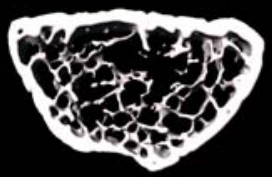

Diabetic+

Dapagliflozin

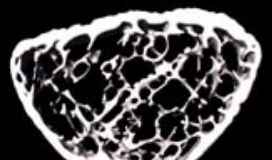

Diabetic+saline

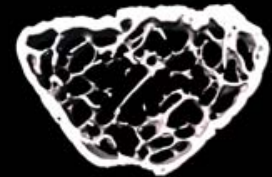

Diabetic+ Liraglutide

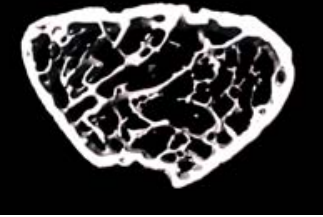

Lean + saline

$\square$ Diabetic + saline

$\square$ Diabetic + dapagliflozin

$\square$ Diabetic + liraglutide
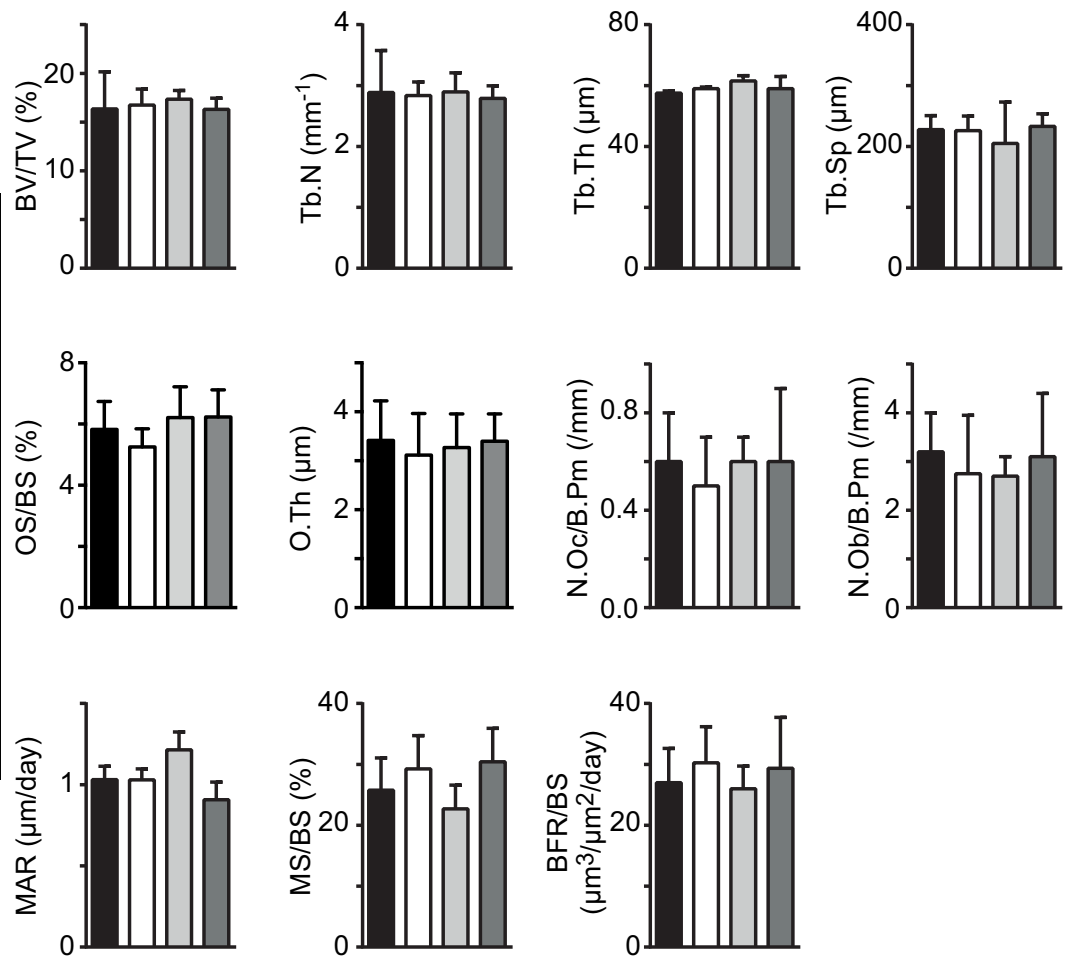

Figure 2 
Bone strength

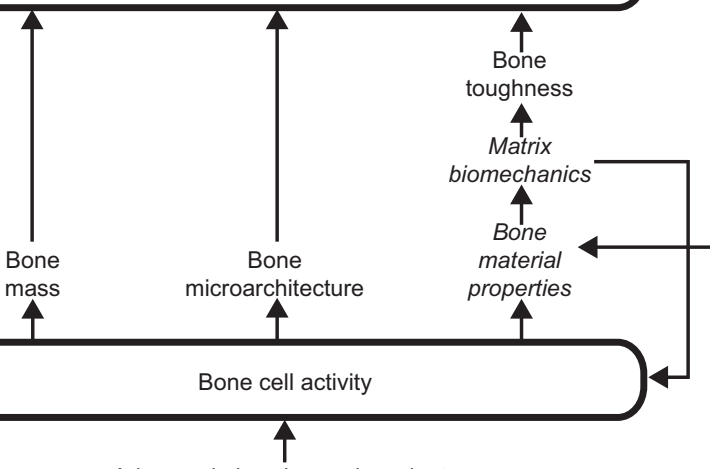

Advanced glycation end-products

$$
\text { Chronic hyperglycemia }
$$

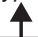

Alteration of glucose metabolism

\section{Figure 4}


Supplementary Figure 1: Schematic representation of the animal experiment design.

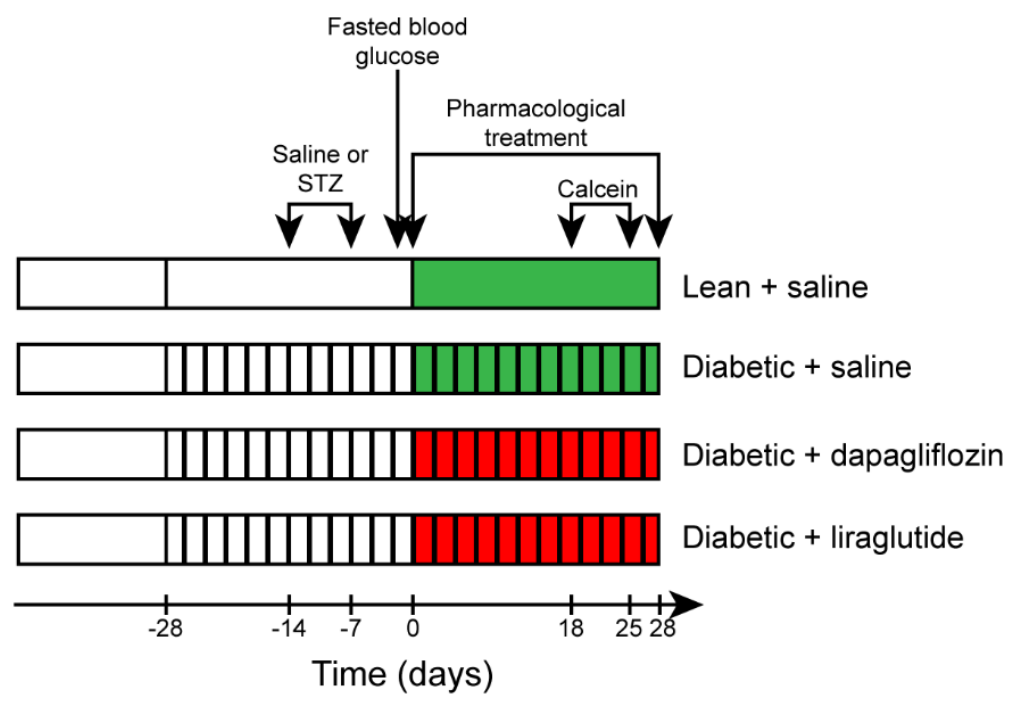

Diet type

$\square$ Standard rodent chow ID High fat diet

Pharmacological intervention $\square$ Saline

Drug 
Supplementary Figure 2: High magnification representative images of TRAP and toluidine blue staining. Black bar $=50 \mu \mathrm{m}$. Arrowheads point at osteoblasts.

TRAP staining

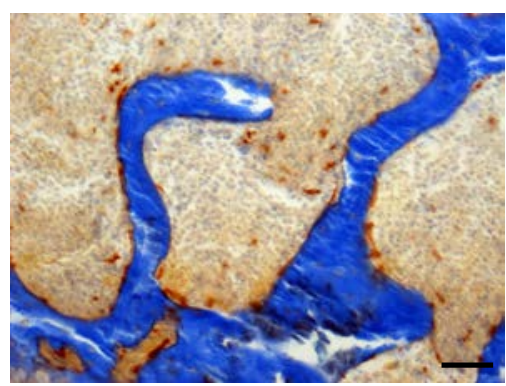

Toluidine blue staining

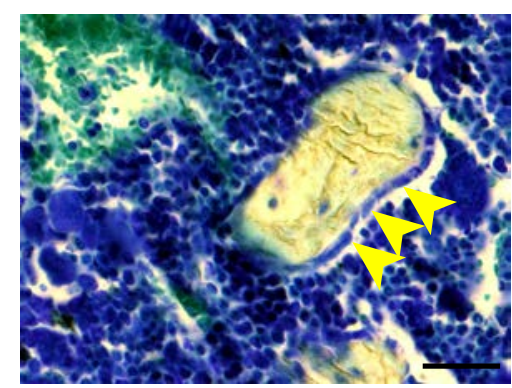


Supplementary Figure 3: Effects of once daily dapagliflozin and liraglutide on bone material properties over the full cortical width. Bone material properties were investigated by Fourier transform infrared imaging in the posterior quadrant. For each parameter, pixel distribution respective to bone area, mean and width have been reported. Normalized enzymatic collagen crosslinks (XL) have been computed as the percentage of total crosslinks. Lean+saline (Black lines and bars), diabetic+saline (dashed lines and white bars), diabetic+dapagliflozin (light grey lines and bars) and diabetic+liraglutide (dark grey lines and bars). Values are means \pm SD for 8 mice. *: $p<0.05$ vs. diabetic + saline.
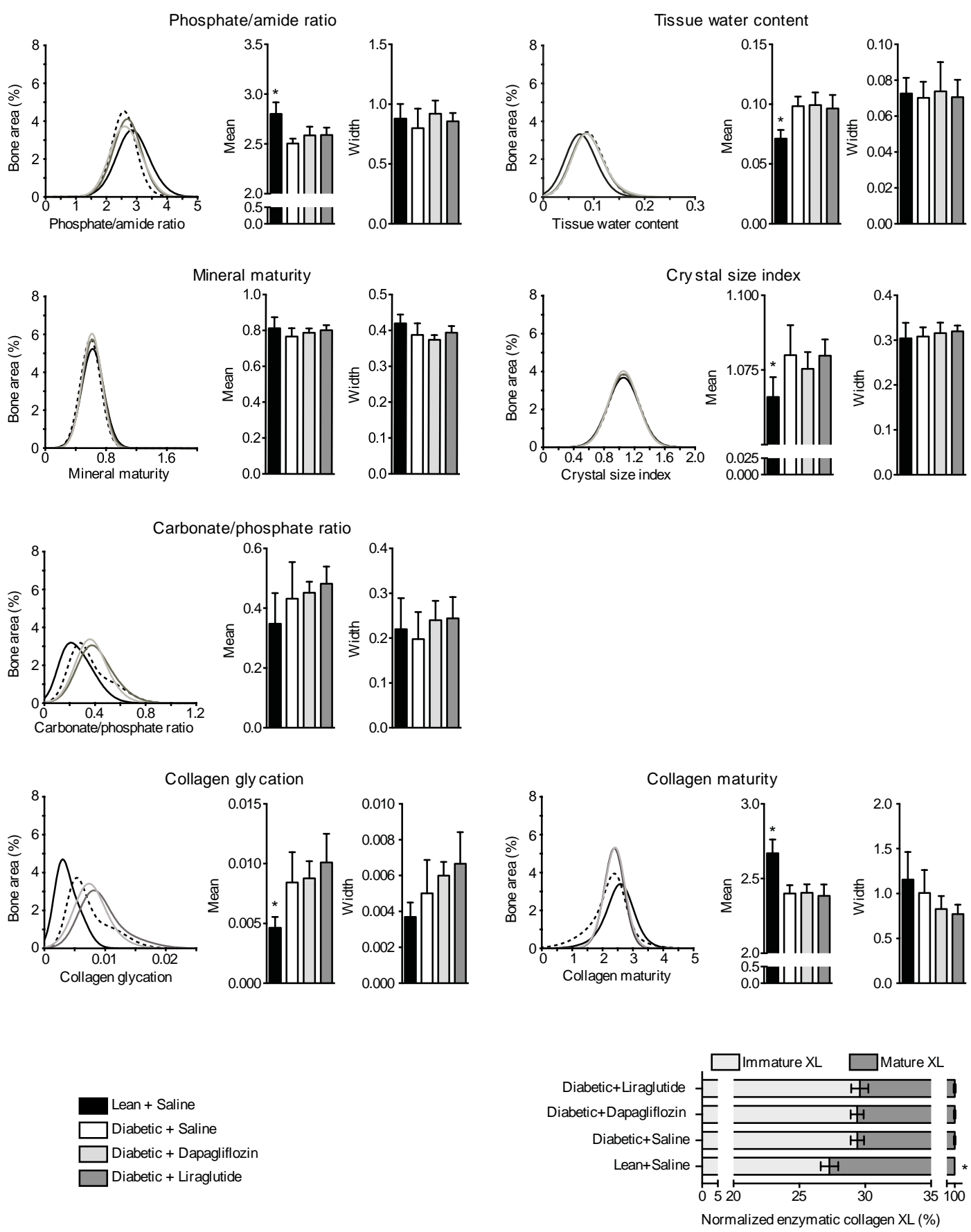
Supplementary Figure 4: Effects of once daily dapagliflozin or liraglutide on bone material properties at bone formation site. Bone material properties were investigated at bone formation site by Fourier transform infrared microspectroscopy. (A) Normalized mean bone spectra acquired at bone formation site after pMMA subtraction. The standard error of the mean of each mean spectrum is shown by the shaded area. (B) Inverted second derivative in the v1,v3 phosphate band. The position of spectral features, identified as peak in the second derivative plot, have been added on the top of each spectra. The number and position of these spectral features have been used in the curve fitting routine to resolve underlying peaks in the $\mathrm{v} 1, \mathrm{v} 3$ phosphate band. (C) Inverted second derivative in the amide I and II bands with their respective spectral features.

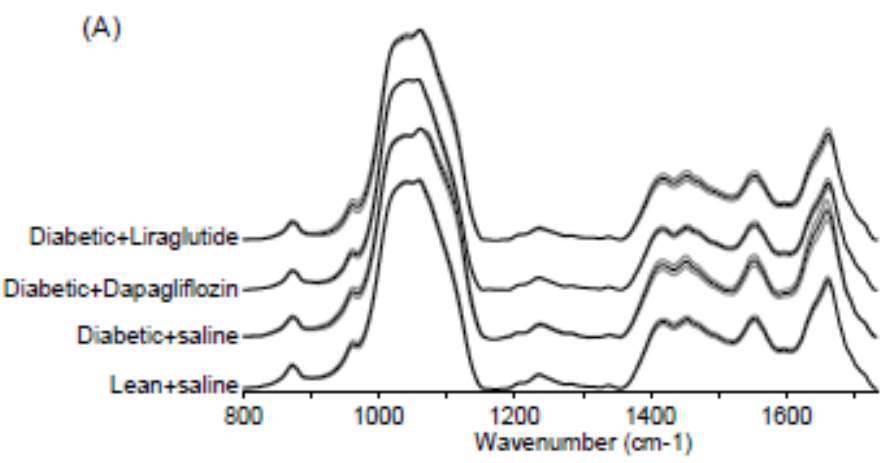

(B)

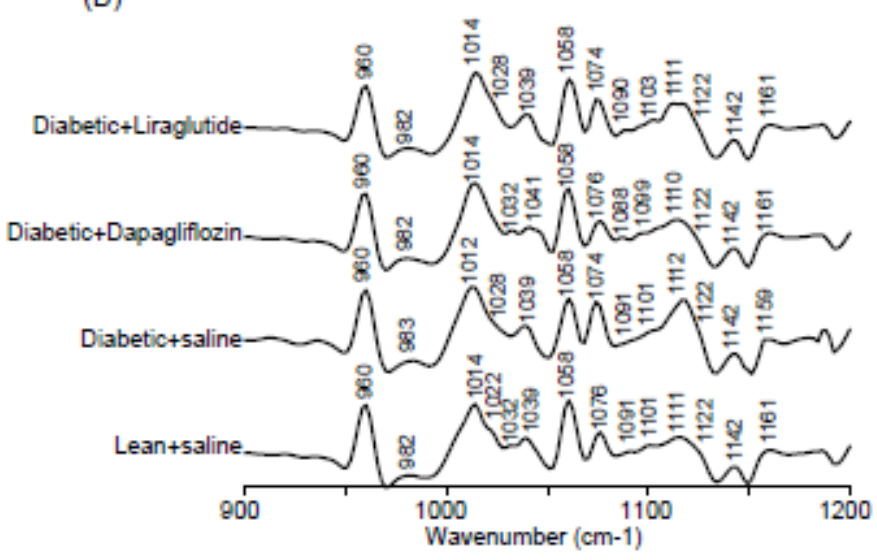

(C)

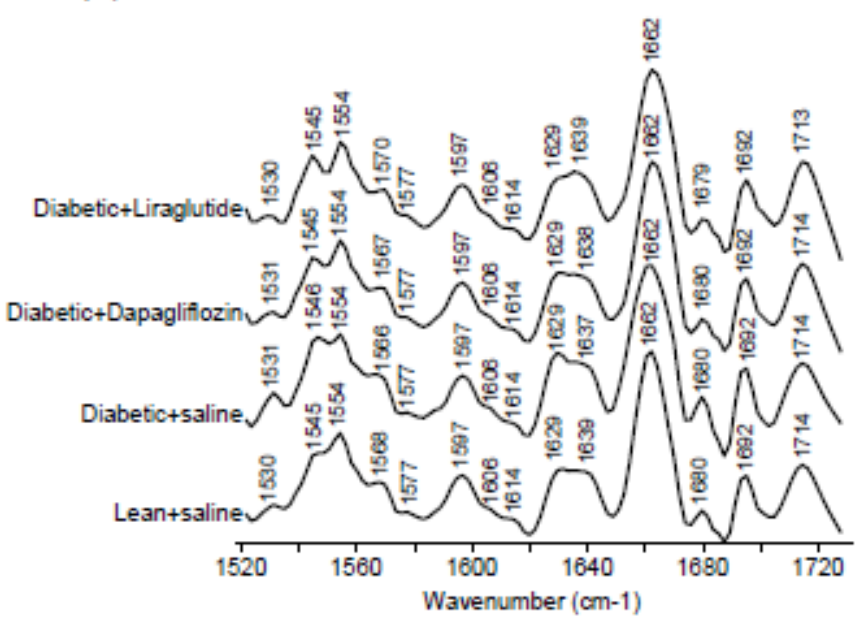


Supplementary Table 1: FTIR band assignment ${ }^{1-8}$

\begin{tabular}{|c|c|}
\hline Position $\left(\mathrm{cm}^{-1}\right)$ & Assignment \\
\hline 960 & $\mathrm{u} 1 \mathrm{PO}_{4}^{3-}$ \\
\hline 982 & $\mathrm{PO}_{3}$ symmetric in brushite, $\mathrm{PO}_{4}{ }^{3-}$ in hydroxyapatite \\
\hline 1014 & $\mathrm{PO}_{4}^{3-}$ in carbonated apatite \\
\hline 1022 & $\mathrm{PO}_{4}^{3-}$ in non-stoichiometric apatite \\
\hline 1032 & $\begin{array}{l}\mathrm{PO}_{4}^{3-} \text { in stoichiometric apatite, advanced glycation end products after } \\
\text { demineralization }\end{array}$ \\
\hline 1039 & Type B carbonate apatite \\
\hline 1058 & $\mathrm{PO}_{4}{ }^{3-}$ in apatite \\
\hline 1076 & $\mathrm{PO}_{4}^{3-}$ in apatite \\
\hline 1091 & $\mathrm{PO}_{4}^{3-}$ in stoichiometric apatite \\
\hline 1101 & \\
\hline 1111 & Poorly crystalline apatite \\
\hline 1122 & $v 6$ ' and $v 6$ " stretch $\mathrm{PO}_{3}$ in $\mathrm{HPO}_{4}^{2-\text { ions }}$ \\
\hline 1142 & $\mathrm{HPO}_{4}{ }^{2-}$ containing apatite \\
\hline 1161 & \\
\hline 1530 & $\beta$-sheet \\
\hline 1545 & $\alpha$-helix \\
\hline 1554 & v(COO-) Glu \\
\hline 1568 & $\beta$-sheet \\
\hline 1577 & v(COO-) Asp \\
\hline 1597 & $\mathrm{v}(\mathrm{C}-\mathrm{C}) \mathrm{Tyr}-\mathrm{O}$ \\
\hline 1606 & $\mathrm{v}(\mathrm{C}-\mathrm{C}) \mathrm{Tyr}-\mathrm{OH}$ \\
\hline 1614 & $\delta(\mathrm{C}-\mathrm{H}) \mathrm{Tyr}-\mathrm{OH}$ \\
\hline 1629 & $\beta$-sheet \\
\hline 1635 & Triple helix \\
\hline 1662 & $\alpha$-helix, pyridinoline \\
\hline 1680 & $\beta$-sheet, deoxypyridinoline \\
\hline 1692 & $\beta$-turn, divalent collagen crosslinks \\
\hline 1714 & $\mathrm{v}(\mathrm{C}=\mathrm{O})$ Asp, Glu \\
\hline
\end{tabular}

\section{REFERENCES}

1. Barth A. Infrared spectroscopy of proteins. Biochim Biophys Acta. 2007;1767(9):1073-1101.

2. Belbachir K, Noreen R, Gouspillou G, Petibois C. Collagen types analysis and differentiation by FTIR spectroscopy. Anal Bioanal Chem. 2009;395(3):829-837.

3. Farlay D, Panczer G, Rey C, Delmas PD, Boivin G. Mineral maturity and crystallinity index are distinct characteristics of bone mineral. J Bone Miner Metab. 2010;28(4):433-445.

4. Gadaleta SJ, Paschalis EP, Betts F, Mendelsohn R, Boskey AL. Fourier transform infrared spectroscopy of the solution-mediated conversion of amorphous calcium phosphate to hydroxyapatite: new correlations between X-ray diffraction and infrared data. Calcif Tissue Int. 1996;58(1):9-16. 
5. Murphy BM, D'Antonio J, Manning MC, Al-Azzam W. Use of the amide II infrared band of proteins for secondary structure determination and comparability of higher order structure. Curr Pharm Biotechnol. 2014;15(9):880-889.

6. Paschalis EP, DiCarlo E, Betts F, Sherman P, Mendelsohn R, Boskey AL. FTIR microspectroscopic analysis of human osteonal bone. Calcif Tissue Int. 1996;59(6):480-487.

7. Paschalis EP, Gamsjaeger S, Tatakis DN, Hassler N, Robins SP, Klaushofer K. Fourier transform Infrared spectroscopic characterization of mineralizing type I collagen enzymatic trivalent cross-links. Calcif Tissue Int. 2015;96(1):18-29.

8. Mieczkowska A, Mansur SA, Irwin N, Flatt PR, Chappard D, Mabilleau G. Alteration of the bone tissue material properties in type 1 diabetes mellitus: A Fourier transform infrared microspectroscopy study. Bone. 2015;76:31-39. 